\title{
Identification and analysis of phosphorylation status of proteins in dormant terminal buds of poplar
}

\author{
Chang-Cai Liu ${ }^{1,2+}$, Chang-Fu Liu ${ }^{3+}$, Hong-Xia Wang ${ }^{4}$, Zhi-Ying Shen ${ }^{5}$, Chuan-Ping Yang ${ }^{1 *}$ and Zhi-Gang Wei ${ }^{{ }^{*}}$
}

\begin{abstract}
Background: Although there has been considerable progress made towards understanding the molecular mechanisms of bud dormancy, the roles of protein phosphorylation in the process of dormancy regulation in woody plants remain unclear.

Results: We used mass spectrometry combined with $\mathrm{TiO}_{2}$ phosphopeptide-enrichment strategies to investigate the phosphoproteome of dormant terminal buds (DTBs) in poplar (Populus simonii $\times$ P. nigra). There were 161 unique phosphorylated sites in 161 phosphopeptides from 151 proteins; 141 proteins have orthologs in Arabidopsis, and 10 proteins are unique to poplar. Only 34 sites in proteins in poplar did not match well with the equivalent phosphorylation sites of their orthologs in Arabidopsis, indicating that regulatory mechanisms are well conserved between poplar and Arabidopsis. Further functional classifications showed that most of these phosphoproteins were involved in binding and catalytic activity. Extraction of the phosphorylation motif using Motif- $X$ indicated that proline-directed kinases are a major kinase group involved in protein phosphorylation in dormant poplar tissues.

Conclusions: This study provides evidence about the significance of protein phosphorylation during dormancy, and will be useful for similar studies on other woody plants.
\end{abstract}

\section{Background}

Dormancy is a key feature of perennial plants. During dormancy the meristem becomes insensitive to growthpromoting signals for a period of time, before it is released and growth resumes [1,2]. Bud dormancy is a critical developmental process that allows perennial plants to survive extreme seasonal variations in climate. The regulation of dormancy is a complex process that is necessary for plant survival, development, and architecture [3,4]. A thorough understanding of regulation mechanisms controlling dormancy in woody perennials would have a variety of applications for genetic improvement of woody trees $[3,5,6]$. Considerable progress has been made in understanding the molecular mechanisms and regulatory pathways involved in bud dormancy [2]. However, until recently such studies focused on regulation at the levels of transcription, posttranscription, and translation [1,7-12]. Despite the importance of dormancy regulation for perennial behavior [3],

\footnotetext{
* Correspondence: yangcp@nefu.edu.cn; zhigangwei@nefu.edu.cn

+ Contributed equally

'State Key Laboratory of Tree Genetics and Breeding (Northeast Forestry

University), 26 Hexing Road, Harbin 150040, China

Full list of author information is available at the end of the article
}

the roles of post-translational modifications, especially protein phosphorylation, remain poorly understood.

The identification of phosphorylation sites within a certain protein cannot provide a comprehensive view of the regulatory role of protein phosphorylation [13-17]. Instead, the simultaneous identification of the phosphorylation status of numerous proteins at a certain developmental stage is required to decode regulatory mechanisms. Large-scale mapping of phosphorylations that occur in response to diverse environmental signals has become an indispensable method for unraveling plant regulatory networks [17-22]. In recent years, advances in mass spectrometry (MS)-based protein analysis technologies, combined with phosphopeptide enrichment methods, paved the way for large-scale mapping of phosphorylation sites in vivo $[13,18,23]$. Specifically, the titanium dioxide $\left(\mathrm{TiO}_{2}\right)$ microcolumn is an effective method to selectively enrich phosphopeptides [17,24-28]. There have been several studies on plant phosphoproteomes. These studies have provided large datasets that allow new insights into phosphorylation events; however, they have been carried out only on herbaceous plants, such as Arabidopsis [22,29-40], oilseed rape [41], rice [42], barley [43], and maize [44]. To date,
Ciomed Central

C 2011 Liu et al; licensee BioMed Central Ltd. This is an Open Access article distributed under the terms of the Creative Commons Attribution License (http://creativecommons.org/licenses/by/2.0), which permits unrestricted use, distribution, and reproduction in any medium, provided the original work is properly cited. 
there have been no reports on the phosphoproteomes of woody plant species, except for the identification of eight phosphorylated poplar P-proteins [45].

Numerous cellular signaling pathways are based on the sequential phosphorylation of an array of proteins $[15,33,46]$. Therefore, the analysis of signaling pathways in plants has often focused on protein kinases. Kinases show catalytic preferences for specific phosphorylation motifs with certain amino acid context sequences $[33,47,48]$. Therefore, identification of in vivo phosphorylation sites can provide important information about the activity of protein kinases in their cellular context.

To better understand the regulation mechanism of phosphoproteins and cellular signaling networks during dormancy, we investigated the phosphoproteome of dormant terminal buds (DTBs) of hybrid poplar (Populus simonii $\times$ P. nigra) using a MS method combined with a $\mathrm{TiO}_{2}$ phosphopeptide enrichment strategy. We identified 161 phosphorylation sites in 161 phosphopeptides from 151 proteins, most of which are associated with binding and catalytic activity. The information gained from this study provides a wealth of resources and novel insights to decode the complicated mechanisms of phosphorylation modifications in poplar. As far as we know, this is the first phosphoproteomic analysis of woody plants.

\section{Results}

\section{Identification and characterization of the} phosphoproteome of DTBs

Total proteins were isolated from DTBs of poplar, and then digested with trypsin in solution. The resulting tryptic peptides were subjected to nanoUPLC-ESI-MS/MS to identify phosphorylation modifications after $\mathrm{TiO}_{2}$ enrichment. In total, 161 unique phosphorylation sites were identified in 161 phosphopeptides from 151 proteins (Table 1, Additional file 1, Additional file 2 and Additional file 3).

Among these phosphorylation sites, 81.3\% (131) of phosphorylation events occurred on Ser and $17.4 \%$ (28) on Thr (Table 1). This finding is consistent with previously reported phosphorylation patterns: $85 \%$ pSer and $10.6 \%$ pThr [22] and $88 \%$ pSer and $11 \%$ pThr [33] in Arabidopsis; and $86 \%$ pSer and $12.7 \%$ pThr in M. truncatula [49].

Table 1 Characterization of identified phosphopeptides, phosphoproteins, and phosphosites

\begin{tabular}{cc}
\hline Items & Number \\
\hline Phosphopeptides $^{1}$ & 161 \\
Phosphoproteins & 151 \\
Phosphorylation sites & 161 \\
Phosphorylated residues (Ser: Thr: Tyr) & $131: 28: 2$ \\
& (81.3\%) (17.4\%) (1.2\%)
\end{tabular}

${ }^{1}$ Number of phosphopeptides counted according to unique sequences containing oxidized methionine or acetylated/phosphorylated residues.
Only $1.2 \%$ (2) of the phosphorylation events of these phosphopeptides occurred on Tyr residue. This is lower than the pTyr values reported for Arabidopsis (4.2\%) and rice (2.9\%) [22,50], but comparable to that reported for Medicago truncatula (1.3\%) [49]. The results of these studies indicate that Tyr phosphorylation in plants is more abundant than once thought [51]. The spectra representing all phosphopeptides and the original detailed data are shown in Additional file 4. As examples, the spectra of phosphopeptides with single pSer, pThr, and pTyr are shown in Figure 1a, c, and 1d, respectively. The spectrum of a phosphopeptide containing two phosphorylated Ser residues is shown in Figure 1b.

The majority (93.8\%) of the 161 phosphopeptides were phosphorylated at a single residue. This value is higher than that reported for Arabidopsis (80.9\%) [22] and $M$. truncatula (66.4\%) [49]. Only 6.2\% of the phosphopeptides from poplar contained two phosphorylated residues, and none were phosphorylated at multiple sites. In Arabidopsis and M. truncatula, 19.1 and $27.1 \%$ of phosphopeptides, respectively, were doubly phosphorylated [22,49] (Additional file 5). This may be a result of different enrichment strategies that show selective or preferred affinity for single or multiple phosphopeptides [52,53].

In a recent phosphorylation mapping study in Arabidopsis, the phosphorylation sites were concentrated outside conserved domains $[22,30]$. To evaluate whether this pattern also occurred among poplar phosphopeptides, we conducted Pfam searches [54] to obtain domain information for the 151 phosphoproteins. We acquired domain information of 134 phosphoproteins (Additional file 1). These data showed that $81.9 \%$ of the phosphorylation sites were located outside of conserved domains (Additional file $6)$, consistent with previous results $[22,30]$. Protein phosphorylation often leads to structural changes in proteins, and such changes can directly modulate protein activity and reflect changes in interaction partners or subcellular localization [14]. Thus, phosphorylations outside conserved domains can be expected to alter protein conformation and functions.

\section{Conservation of phosphoproteins and phosphosites between poplar and Arabidopsis}

We compared phosphorylation patterns of orthologous proteins between poplar and Arabidopsis to analyze conservation between their phosphoproteomes. Additional file 7 shows orthologous proteins in poplar and Arabidopsis. Phosphorylation sites in poplar that were absent from their equivalent sites in proteins from other plant species were considered to be novel phosphorylation sites (Additional file 2).

We found only 10 phosphoproteins that were unique to poplar, and the rest had ortholog(s) in Arabidopsis. Among these ortholog(s), more than 75\% (110) were 


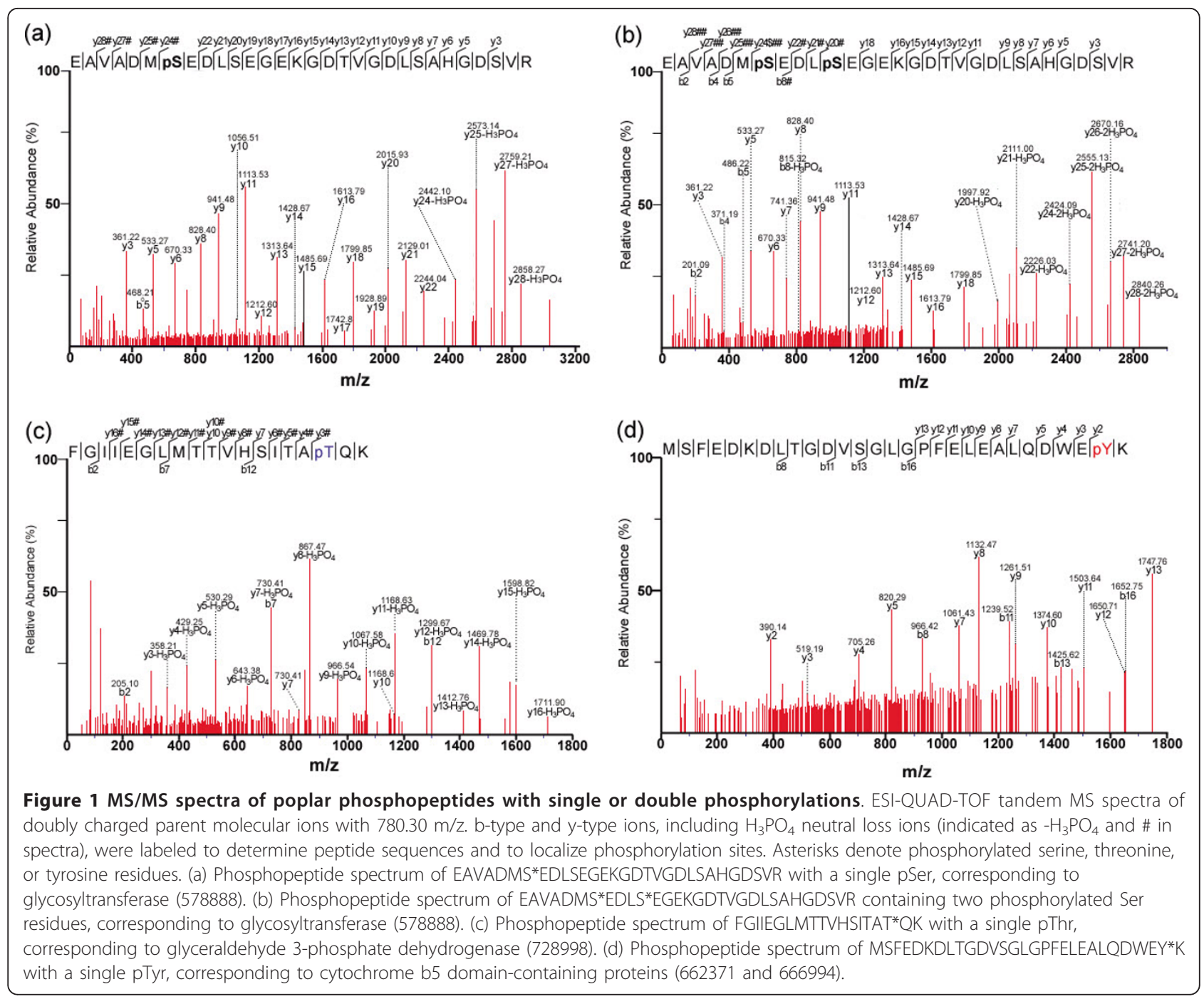

phosphoproteins, and almost half of them were phosphorylated at equivalent site(s) or neighboring site(s) in poplar and Arabidopsis (Table 2; Table 3). Among the identified phosphosites, 127 (84.1\%) were conserved across the two species. The proteins containing these sites were involved in various physiological processes (see Additional file 8). Of the 127 conserved sites, only 62 were phosphorylated in the Arabidopsis ortholog(s), and the remaining 65 were novel phosphorylation sites in poplar (Additional files 8 and 9). Note that the residues at the equivalent sites of ortholog(s) are potential phosphorylation sites, as shown in Additional file 8. For example, two different poplar plasma membrane $\mathrm{H}$ +-ATPase isoforms (PtrAHA10, 826518 and PtrAHA11, 422528) and their Arabidopsis homologs (At1g17260 and At5g62670) were phosphorylated at their well-conserved C-terminal domain (Figure 2a). In Populus trichocarpa, the Lhcb1 protein exists as three distinct isoforms; Lhcb1.1 (568456), Lhcb1.2 (652073) and
Lhcb1.3 (715463). In the present study, we identified two previously unknown phosphorylation sites at the Nterminus; Thr38, which is well conserved across the Lhcb1 isoforms of several plants, and Thr39, which is not conserved across Lhcb1 isoforms of other plants, but is present as a non-phosphorylated residue in the Lhcb1 isoforms of Arabidopsis and spinach (Figure 2b).

Table 2 Conservation of phosphosites and phosphoproteins between poplar and Arabidopsis

\begin{tabular}{rc}
\hline Phosphoproteins & Number \\
\hline 1) Proteins unique to poplar & 10 \\
3) Proteins with ortholog(s) in Arabidopsis & 141 \\
4) Proteins whose ortholog(s) are phosphorylated & 110 \\
5) Equivalent site(s) are phosphorylated in ortholog(s) & 62 \\
6) Other site(s) are phosphorylated in ortholog(s) & 48 \\
\hline
\end{tabular}


Table 3 Similarities of phosphoproteins/phosphosites conserved between poplar and Arabidopsis

Similarity with closest homologs in Arabidopsis Number of phosphoproteins Number of phosphosites Conservation of phosphosites Phosphosites in Arabidopsis counterparts

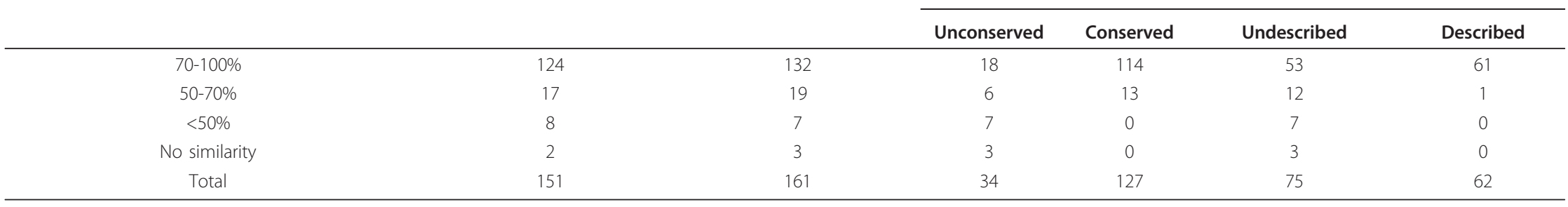




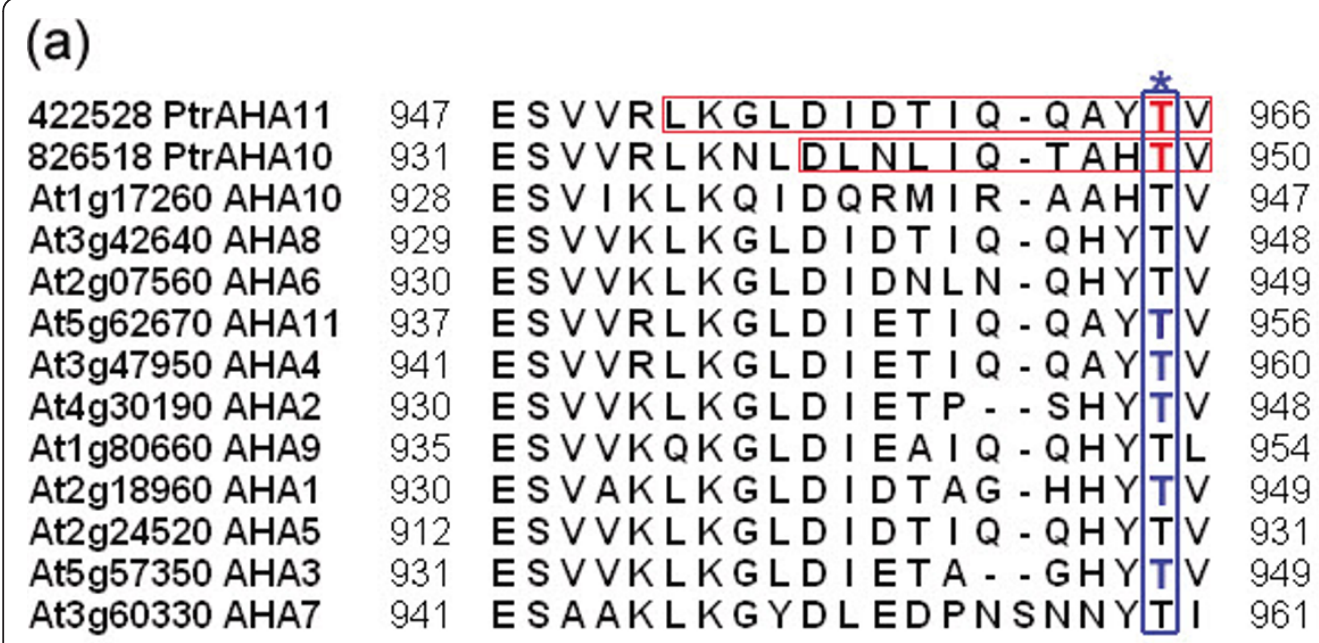

(b)

652073 PtrLhcb1.2 715463 PtrLhcb1.3 568456 PtrLhcb1.1 At2g34430 Lhcb1.4 At1g29930 Lhcb1.3 At1g29910 Lhcb1.2 At2g34420 Lhcb1.5 At1g29920 Lhcb1.1 CAJ77389 SpLhcb1.3 CAJ77390 SpLhcb1.2 CAJ77391 SpLhcb1.1
27

27

27

27

27

27

25

27

27

27

27

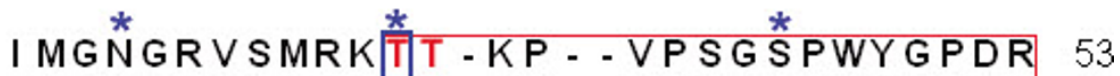
I MGNGR VSMRKTTT - KP - - VPSGSPWYGPDR 53 L MGNGR VSMRKTTT - KP - - VSSGSPWYGPDR 53 VF G T GR I TMRK-ASKPT - GPSGSPWYGSDR 54 VL G SGR VTMRKTTVAKPK - GPSGSPWYGSDR 55 VL G SGRVTMRK TVAKPK - GPSG SPWYGSDR 55 VL GSGRVTMRKTTVAKPK - GPSGSPWYGSDR 53 VL G SGRVTMRKTTVAKPK - GPSGSPWYGSDR 55 I I GEGR I TMRKTAGKPKTVQSSSPWYGPDR 56 I L GEGRVTMRKTAGKPKNVSSGSPWYGPDR 56 M I GEGR I SMRK S A GKPKNVS S G SPWYGPDR 56
\end{abstract}

Figure 2 Conservation of phosphorylation sites between poplar proteins and homologs in other plants. Sequence alignments were conducted to determine conservation of phosphorylation sites among homologs. Gaps were introduced to ensure maximum identity. Fine red boxes represent phosphopeptides identified in this study. Phosphorylation sites identified in our study are shown in red bold font. Previously identified phosphorylation sites in Arabidopsis are indicated blue bold font. Well-conserved phosphorylation sites are shown within blue box in bold. Phosphorylation site is marked with an asterisk. (a) Phosphorylation sites conserved across plant plasma membrane H+-ATPases (AHA) orthologs. (b) Phosphorylation sites conserved across plant chlorophyll-a/b-binding protein 1 (Lhcb1) orthologs.

Recently, overlaps among Medicago, rice, and Arabidopsis phosphoproteomes suggested that the phosphoproteomes are similarly conserved among various herbaceous plant species, and that overlaps are not specifically dependent on experimental conditions [50]. In this work, we observed overlaps between the poplar and Arabidopsis phosphoproteomes, providing additional evidence that phosphoproteomes overlap across plant kingdoms.

Unique phosphorylation sites of poplar proteins, compared with orthologs in other plants

Many physiological features of woody plants are not reflected in herbaceous models, e.g., Arabidopsis or rice. In our study, several poplar phosphoproteins were highly conserved with their Arabidopsis ortholog(s), but their corresponding phosphorylation sites were not conserved (Additional file 9). For example, the poplar 20S proteasome subunit protein (PtrPBA1) shared high sequence similarity with its orthologs in Arabidopsis (AtPBA1), Medicago truncatula (MtPBA1), and rice (OsPBA1). In PtrPBA1 (673509 and 819127), there is a C-terminal motif that includes a pSer residue at position 231. This motif is conserved across two other PtrPBA1 isoforms (Figure 3a), but the equivalent sites are substituted with a non-phosphorylatable residue in the homologs in the other three species (Figure 3a). The poplar glucose-6-phosphate 1-dehydrogenase isoforms (PtrG6PD, 736146 and 641721) are another good example; they share high sequence similarity with their homologs in Arabidopsis (AtG6PD), M. truncatula (MtG6PD), and rice (OsG6PD). However, PtrG6PD (736146) is phosphorylated at the N-terminus at residue Thr25 (Figure 3b), which is conserved across poplar G6PD isoforms, but the residues at the equivalent position in G6PD isoforms of Arabidopsis, Medicago, and rice are non-phosphorylatable. Interestingly, 


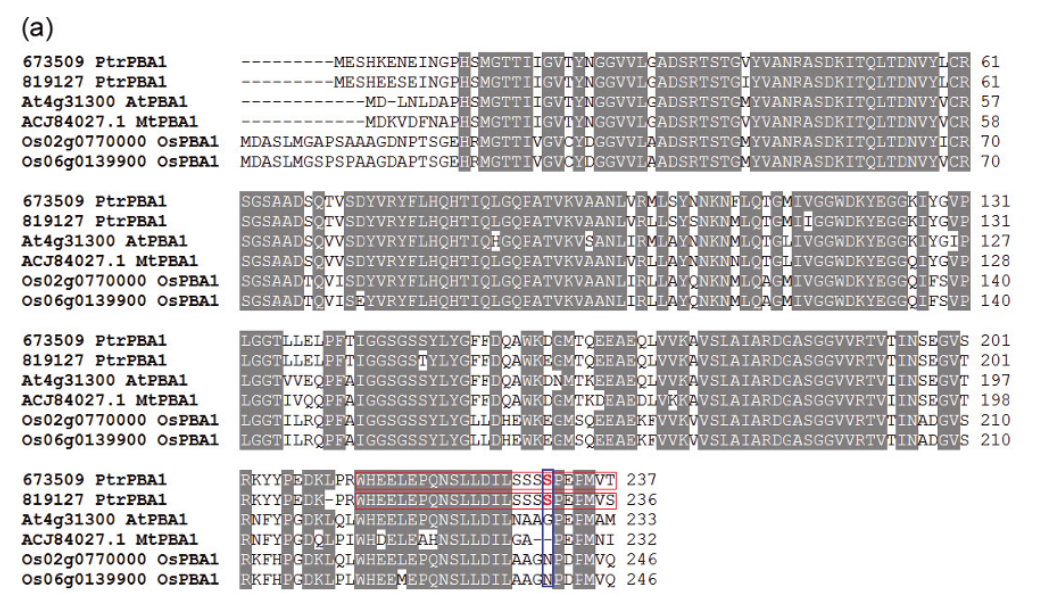

(b)

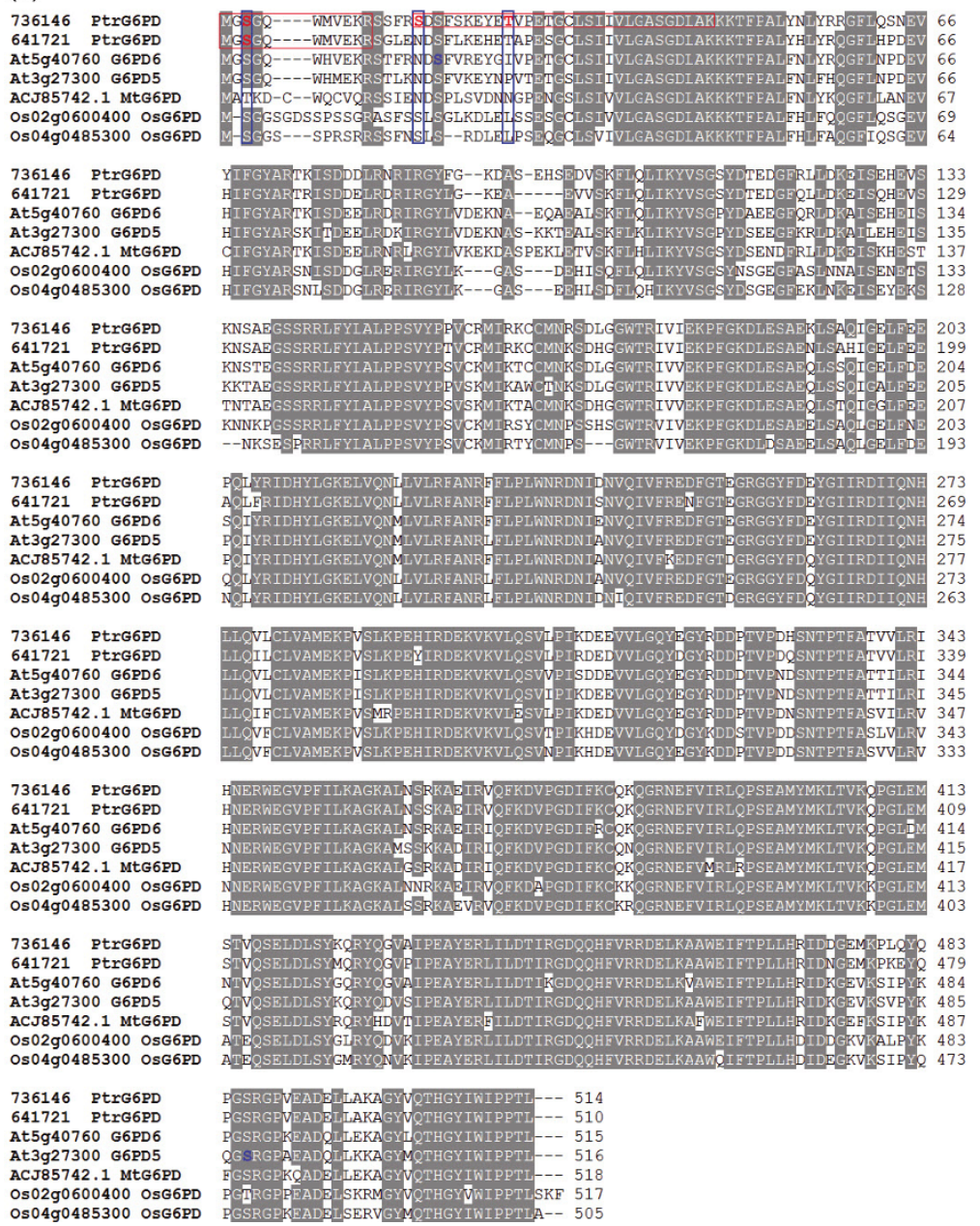

Figure 3 Sequence alignment of poplar phosphoproteins and their closest Arabidopsis homologs to identify unique phosphosites in poplar. Asterisk indicates phosphorylation site. Fine red boxes show phosphopeptides identified in this study. Phosphorylation sites identified from poplar in our study are shown in red bold font. Blue bold boxes show non-conserved phosphorylation sites. (a) Sequence alignment with all PBA1 orthologs. (b) Sequence alignment with all G6PD orthologs. 
pSer16 is conserved across rice G6PD orthologs, but it is substituted with a non-phosphorylatable Asn residue in its Arabidopsis and Medicago orthologs (Figure 3b). These findings suggest that there are unique mechanisms regulating phosphorylation in poplar.

In summary, identification of new phosphorylation sites can provide significant biological insights about the cellular mechanisms of signaling activation and inhibition. Although many phosphorylation sites have been identified in Arabidopsis from the PhosPhAt database [55], we identified 99 novel phosphosites and 41 novel phosphoproteins in poplar in the present study. These novel phosphoproteins and phosphorylation sites could provide useful data to identify components of phosphorylation-dependent signal cascades, and to determine the function of phosphorylation events in responses to specific environment signals.

\section{Classification of the DTB phosphoproteome}

Figure 4a shows the results of a euKaryotic Orthologous Groups (KOG) classification analysis [56] of the 151 phosphoproteins. The KOG classification of the identified phosphoproteins and all proteins encoded in the $P$. trichocarpa genome are shown in Additional files 10 and 11, respectively. Of the 151 phosphoproteins, 129 were assigned a KOG ID according to the KOG classification. The remaining phosphoproteins were poorly annotated and could not be assigned to any KOG group. The classified proteins were further divided into various subgroups: the largest functional subgroup consisted of 19 phosphoproteins, which were assigned to the J subgroup (translation, ribosomal structure, and biogenesis), 16 phosphoproteins were assigned to the G subgroup (carbohydrate transport and metabolism), and 15 phosphoproteins were assigned to the O subgroup (posttranslational modification, protein turnover, chaperones) (Figure 4a and Additional file 11).

Functional annotation of phosphoproteins was also conducted using the Blast2Go program [57]. Sequences were searched against the non-redundant (NR) protein database at NCBI. These identified phosphoproteins were categorized into seven major classes with diverse functions (Figure 4b): $80.6 \%$ were related to binding affinity (45.3\% to binding affinity associated with regulation of gene expression and catalytic activity, and $35.3 \%$ to binding affinity related to carbohydrate transport, biosynthesis, and metabolism). The rest were categorized as having structural molecule activity (7.1\%), translation $(5.3 \%)$ or transcription regulator activity $(2.9 \%)$, membrane proteins with transporter activity (2.9\%), and enzyme regulator activity (1.2\%) (Figure 4b). In this study, most of the identified phosphoproteins were involved in binding and catalytic activity, consistent with previous studies [22,32,33].

\section{Potential protein kinases involved in signal transduction during dormancy in poplar}

Confirmed phosphorylation sites are footprints of kinase activities. To date, several kinases have been documented in Arabidopsis, and their substrate spectra and functional interactions have mainly been deciphered by large-scale investigations of phosphoproteins [22,33]. However, little is known about the kinases involved in regulating dormancy in plants. To identify the protein kinases responsible for phosphorylation of the phosphosites identified in this study, we obtained putative phosphorylation motifs from the phosphopeptide dataset using the Motif-X software tool (Figure 5). This tool extracts overrepresented patterns from any sequence dataset by comparing it to a dynamic statistical background [58]. Four significantly enriched phosphorylation motifs were extracted from the identified DTB phosphopeptides dataset (Figure 5b). One of the enriched phosphorylation site motifs resembled a known motif in proline-directed kinases (pS/pTP). This was also supported by the alignment of all the identified DTB phosphorylation sites (Figure 5a). The identity of the second enriched motif was unknown, and had no counterparts in any known kinases. The third enriched phosphorylation motif showed high similarity to a motif found in members of the casein kinase II subfamily (pS/pTXXE/D). Members of this family can phosphorylate a wide variety of plant proteins in vitro. The fourth enriched motif was similar to the 14-3-3 binding motif ( $\mathrm{RXXpS/pT)}$. Kinases with this motif regulate the activities of the vacuolar potassium channel KCO1 and the vacuolar ATPase [59] (Figure $5 \mathrm{~b})$. These results suggest that proline-directed kinases could be the major kinase group involved phosphorylation of these identified proteins during dormancy in poplar (Figure 5).

\section{Discussion}

A series of differential expression profiling analyses of the induction, maintenance, and release of bud dormancy made it possible to identify a large set of dormancy-related candidate genes [1,9-12,60-66]. These genes were mainly involved in ABA signaling pathways, cold and oxidative responses, flavonoid biosynthesis, flowering time, and circadian regulation $[66,67]$. Although there is increasing information available about the roles of genes and their products in dormancy, very little is known about the relevance of protein phosphorylation in dormancy. To address this, in this work, we identified the phosphorylation status of proteins in dormant terminal buds of poplar using mass spectrometry combined with $\mathrm{TiO}_{2}$ phosphopeptideenrichment strategies. However, it remains unknown whether these phosphoproteins identified in dormant buds in this study actually participate in dormancy-related processes. To interpret the significance of the presence of 


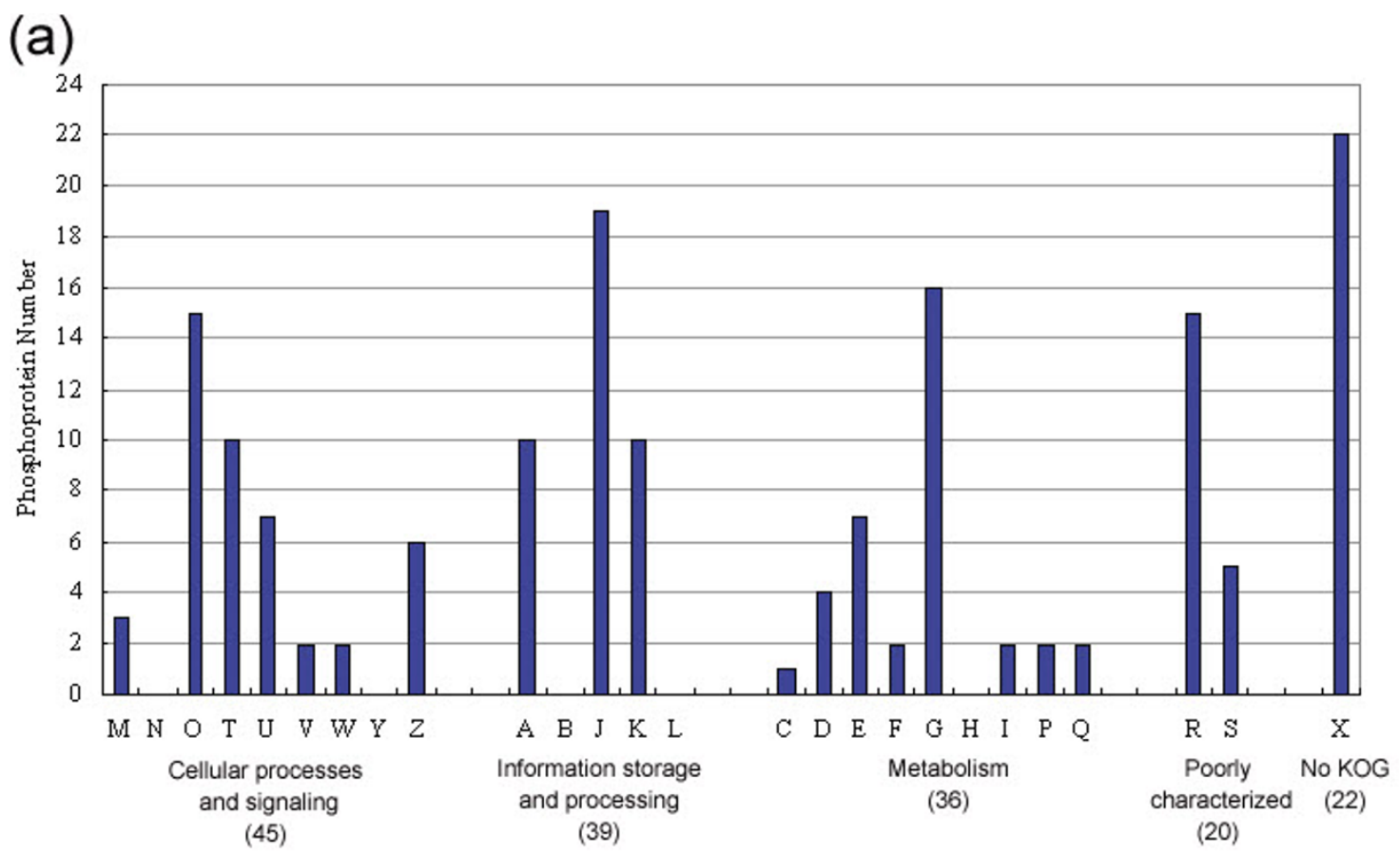

(b)

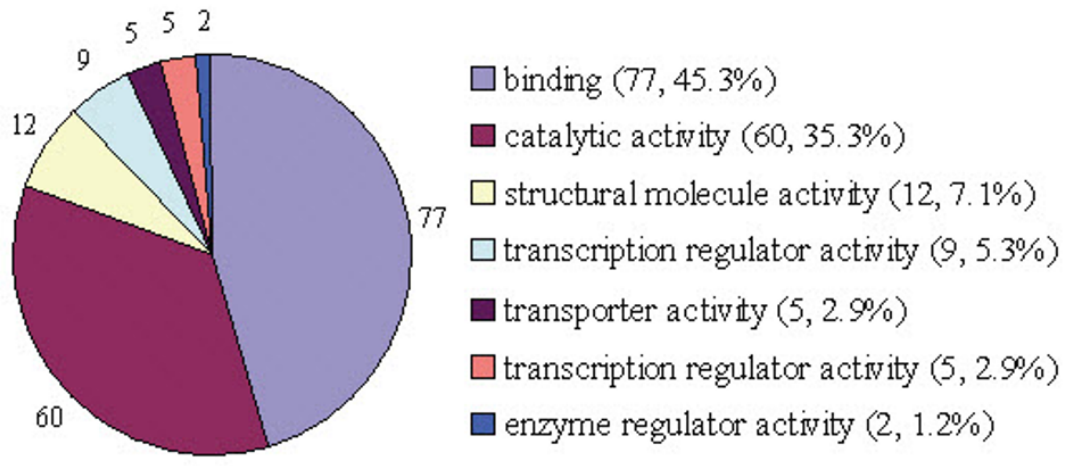

Figure 4 KOG and molecular functional classification of phosphoproteins identified from poplar DTBs with verified phosphopeptides $(\boldsymbol{n}=\mathbf{1 5 1})$. (a) KOG classification of phosphoproteins identified from poplar DTBs; $X$ represents phosphoproteins without KOG classification; (b) Molecular functional classification of identified phosphoproteins.

these phosphoproteins in dormant buds, we compared the identified phosphoproteins with previously reported dormancy-related genes and their products. Notably, some of these phosphoproteins were well matched to homologs of known dormancy-related candidate gene-products identified in previous studies of various species. Some of these common proteins of interest are briefly discussed in the context of dormancy.

\section{Phosphoproteins involved in dormancy-related signal transduction}

Abscisic acid (ABA) is the major plant hormone involved in growth, dormancy, and cold acclimation [68]. The
ABA signaling pathway is regulated by reversible protein phosphorylation mediated by protein kinases and phosphatases [68]. Genetic evidence demonstrated that sucrose non-fermenting (SNF)-like protein kinase, receptor-like protein kinase (LRK), and protein phosphatases 2C (PP2Cs) encoded by $A B I 1$ and $A B I 2$ are important regulators of the ABA signaling pathway, which plays an important role in the induction or release of bud dormancy [5,6,10,63,68-72]. In this work, three SNF1-type kinases in poplar $(299214,818055$, and 828986) containing the phosphopeptide "DGHFLKTSCGPSPNYAAPEVISGK", and one leucine-rich repeat receptor-like protein kinase (LRK, 422370) were phosphorylated 
(a) Phosphorylation site alignment

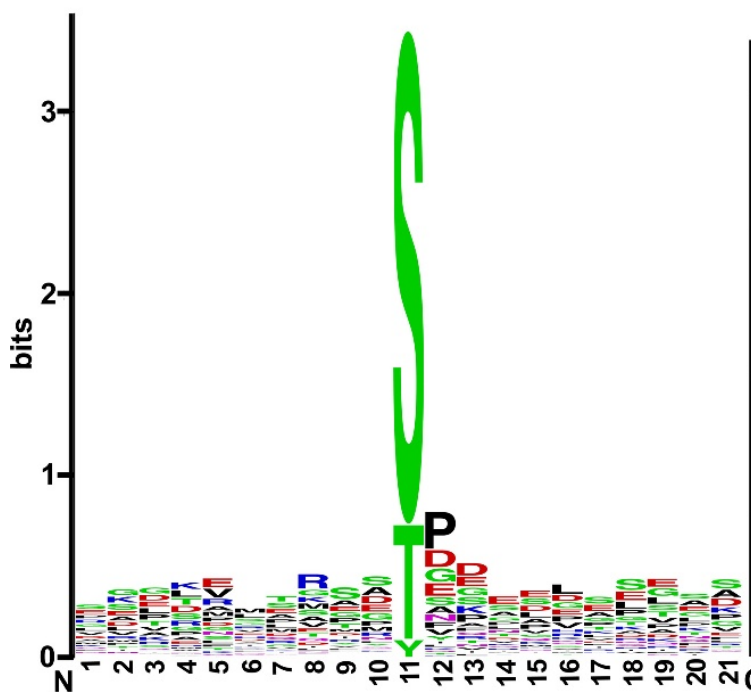

(b) Phosphorylation motifs

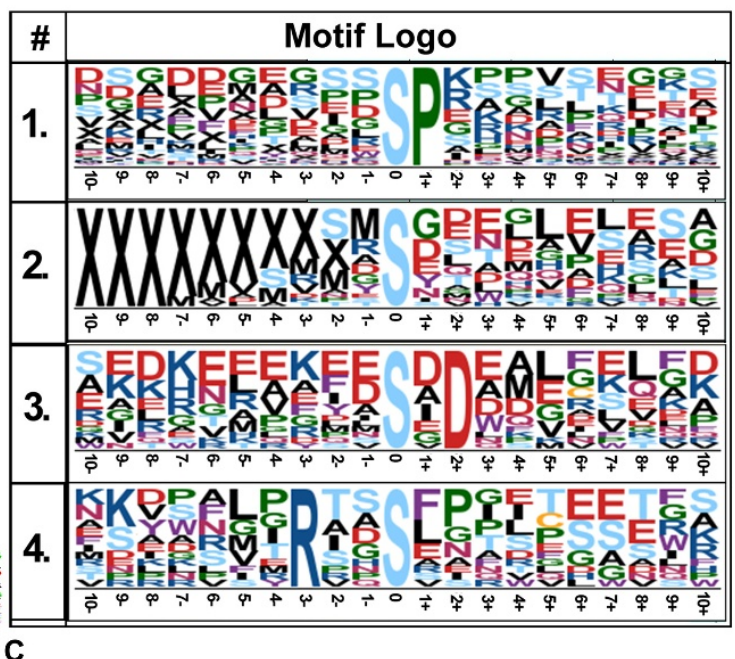

Figure 5 Sequence alignment of phosphorylation sites and extraction of significantly enriched phosphorylation motifs. (a) Amino acid sequence around the phosphorylated amino acid based on alignment of all phosphorylation sites from the identified DTBs phosphopeptide dataset using Weblogo. (b) Motif-X-extracted motifs from entire phosphopeptide dataset. JGl Populus trichocarpa v1.1 protein database was used as the background database to normalize the score against a random distribution of amino acids. Note that only those phosphorylated amino acids that were confidently identified as the exact site of phosphorylation were used for the analysis (see "Materials and Methods" for detailed description). Motif 1, Pro-directed kinase motif ( $n=40)$; Motif 2, Unknown phosphorylation motifs $(n=20)$; Motif 3, CKII motif ( $n=17)$; Motif 4, 14-3-3 binding motif $(n=13)$.

(Additional files 12 and 13). These phosphorylation sites were all well conserved, and corresponding phosphosites were identified in Arabidopsis (Additional file 12). In the case of PP2C, the Ser131 in the phosphopeptide "VSGMIEGLIWpSPR" from PP2C (554898, 587195) was identified as a novel phosphorylation site (Additional file 14). Calmodulin ( $\mathrm{CaM})$ and the CaM-binding protein play an important role in $\mathrm{Ca}^{2+}$ signaling, which is related to bud dormancy $[61,64,70,73,74]$. In this study, two CaM family proteins (729432 and 823453) were phosphorylated (Additional file 3 and Additional file 13); however, the corresponding site has not been identified as a phosphorylation site in their respective Arabidopsis counterparts, AT1G56340.1 and AT5G61790.1.

Phosphoproteins involved in auxin responses and growth development related to dormancy

The auxin-sensitive Dormancy-associated/auxinrepressed (DAAR) gene is associated with bud dormancy $[66,75,76]$. In this study, one DAAR protein (647948) showed three isoforms with respect to phosphorylation status, the three forms respectively phosphorylated at Thr61, Thr63, and Thr70 (Additional file 3 and Additional file 13). These corresponding sites have not been identified as phosphorylation sites in its homolog in Arabidopsis, the DAAR protein (AT1G28330.1). Interestingly, the Arabidopsis DAAR protein is phosphorylated at its conserved Thr28 and Thr29 residues [33].
Vernalization independence 4 (VIP4) interacts with the FLOWERING LOCUS C-LIKE MADS-BOX PROTEIN (FLC) to activate FLC, leading to inhibition of flower development [77-79]. They are key components in the regulatory pathway of cold-mediated bud dormancy induction and release [4,77]. In our study, we observed that poplar VIP4 (569930) was phosphorylated at Ser225 (Additional file 3 and Additional file 13); the corresponding site in its Arabidopsis homolog (AT5G61150.2) is also known to be phosphorylated [50]. The mei2-Like $(\mathrm{ML})$ genes, which play roles in plant meiosis and development [80], were preferentially expressed in dormant buds of leafy spurge [66]. In this study, two phosphorylation sites were respectively identified on the $\mathrm{N}$ - and Cterminus of two isoforms of poplar mei2-like proteins (714870 and 410877), which are homologous to Arabidopsis ML (AT1G29400.2) (Additional file 3 and Additional file 13). The corresponding site at the N-terminus in Arabidopsis ML is known to be phosphorylated [50], while the C-terminal phosphorylation site was novel.

\section{Phosphoproteins involved in dormancy-related cold stress response}

Dehydrins (DHNs) are Group II (D-11 family), late embryogenesis abundant (LEA) proteins that accumulate in response to water deficit induced by drought, low temperature, or salinity [81-84]. Certain DHNs play a vital role in bud dormancy and cold acclimation of trees 
$[1,12,66,85-88]$. Phosphorylation of their S-segment is required for targeting to the nucleus [89-91]. In this study, three DHN proteins were phosphorylated in regions outside of the $\mathrm{S}$-segment, one (663123) belongs to the $K_{n}$ type of DHNs, one (571250) belongs to the $K_{n} S$ type of DHNs, and the other (818850) belongs to the $\mathrm{SK}_{\mathrm{n}}$ type of DHNs (Additional file 3 and Additional file 13). Heat shock proteins (HSP) function as molecular chaperones, and are induced by various environmental stress, such as cold, salinity, and oxidative stress [92]. Recent data suggested that they are also involved in the process of bud dormancy $[12,93,94]$. A phosphorylation event on an HSP was identified in Arabidopsis [22,40]. Here, two HSP70s (657150 and 769322), one HSP90 (652330), and one HSP26 (832078) were phosphorylated in poplar (Additional file 3 and Additional file 13).

\section{Phosphoprotein associated with dormancy-related flavonoid biosynthesis}

Many genes related to flavonoid biosynthesis are significantly regulated during the release of dormancy, such as acetyl-CoA carboxylase (ACCase), chalcone synthase, chalcone isomerase, and flavonol synthase [12,65-67]. Acetyl-CoA carboxylase (ACCase) catalyzes the formation of malonyl-CoA, which is the substrate for biosynthesis of fatty acids and secondary metabolites, such as flavonoids and anthocyanins [67]. In this work, one putative ACCase (736443) was phosphorylated at Ser94 and Ser95 (Additional file 3 and Additional file 13). There have been no reports of phosphorylation of its homolog in Arabidopsis (AT5G16390.1). Interestingly, we also found another phosphorylation event related to flavonoid biosynthesis; polyphenol oxidase (PPO) (275859) was phosphorylated at Ser452 (Additional file 3 and Additional file 13). The poplar PPO has no counterparts in Arabidopsis, but it shows homology to aureusidin synthase (AS) in Antirrhinum majus, a flavonoid synthase enzyme that catalyzes the formation of aurones from chalcones [95]. To our knowledge, this is the first report of a specific phosphorylation site in a plant flavonoid synthase. The existence of this site suggests that phosphorylation may regulate its functions.

\section{Phosphoproteins involved in transport related to dormancy}

The plasma membrane $\mathrm{H}+$-ATPase (AHA) is responsible for the transport of protons out of the cell through the membrane [96]. The AHA gene is strongly expressed during dormancy transition, and contributes to changes in the plasma membrane [12]. The regulation of AHA is controlled by phosphorylation of one Thr residue in the wellconserved C-terminal domain [97,98]. In the AHA family in Arabidopsis, the well-conserved $\mathrm{Thr}$ residue is phosphorylated in response to stress [37,42,97]. Here, the exact Thr site (Thr949) in the C-terminus of poplar AHA10 (826518), and its corresponding site in AHA11 of poplar (422528) were both phosphorylated (Figure 2a). Another example of a transport protein is ATP-binding cassette $(\mathrm{ABC})$ transporters, which are integral membrane proteins that transport a wide variety of substrates, such as ABA, auxin, and some plant secondary metabolites across cellular membranes $[99,100]$. Genes encoding ABC transporters are regulated during dormancy transition $[11,12,66]$, suggesting that they are linked with dormancy. Here, two ABC transporter family proteins (554850 and 800153) were phosphorylated at Thr55 (Additional file 3 and Additional file 13). The corresponding site is phosphorylated in its homologs in rice, Arabidopsis, and Medicago $[42,49,50]$.

\section{Phosphoproteins involved in protein synthesis related to dormancy}

Some genes and proteins involved in protein biosynthesis play a role in the mechanism of bud dormancy release $[12,60,101]$. Phosphorylation of ribosomal proteins can affect protein synthesis by altering ribosome structure [45]. In the present work, six $60 \mathrm{~S}$ acidic ribosomal proteins including P0-, P1-, P2-, and P3-types were phosphorylated close to their conserved $\mathrm{C}$ terminus, consistent with results reported elsewhere [45]. However, the pSer at position 2 on the 40S ribosomal protein S12 of poplar (RPS12, 714910) was novel (Additional file 15). Recent evidence suggests that phosphorylation of Ser2 plays an important role in regulating nucleocytoplasmic shuttling of eukaryotic translation initiation factor 5A (eIF5A) in plant cells [102-104]. Here, four poplar eIF5A proteins (717121, 832646, 835953, and 724093) were phosphorylated at their well-conserved serine residue and acetylated at their Nterminus (Additional file 16). Phosphorylation regulates the function and/or location of translation elongation factor 1A (eEF1A), which is involved in protein biosynthesis and signal transduction [105-107]. Here, five eEF1A isoforms (256777, 655943, 675976, 655949, and 720367) from poplar, all containing the phosphopeptide pSVEMHHEALQEALPGDNVGFNVK (Ser279) were novel phosphoproteins (Additional file 17).

\section{Phosphoproteins involved in electron transport or energy pathways}

There are increases in expressions of some genes involved in energy pathways during bud release, including glyceraldehyde-3-phosphate dehydrogenase (GAPC) and phosphoenolpyruvate carboxylase (PEPC) $[11,12,60,93]$. Here, three GAPC isoforms $(821843,575307$ and 728998) and three PEPC isoforms (552645, 745223, and 728315) were phosphorylated (Additional file 13 and Additional file 3). 
The light harvesting complex protein Lhcb1, which is essential for light electron transport, is significantly regulated during bud release $[11,63,66]$. Reversible phosphorylation of Lhcb1 is important for distributing absorbed light energy between the two photosystems [108,109]. As reported in other experiments on Arabidopsis [33,110] and spinach, Lhcb1 proteins are phosphorylated at several Thr and Ser residues in their amino terminus [108]. Here, we identified two previously unknown phosphorylation sites on the poplar Lhcb1 protein; the conserved Thr38 phosphosite and the unconserved Thr39 phosphosite (Figure $2 b$ ).

In summary, this information on phosphoproteins in dormant poplar provides a useful dataset, and provides new insights for exploring the relevance of phosphorylation for dormancy. However, further research, e.g., comparing proteomes between dormant/non-dormant tissues, is required to clarify the roles of phosphorylation in the dormancy process.

\section{Conclusions}

Many physiological features of woody plants are not reflected in the herbaceous model Arabidopsis or in rice. Therefore, it is important to determine phosphorylation sites in poplar proteins, and to determine the roles of these phosphorylations in modifying protein function during growth and development. To date, there have been no extensive studies on the poplar phosphoproteome. In this work, we conducted a detailed analysis of the phosphoproteome of dormant poplar buds using an MS method and $\mathrm{TiO}_{2}$ phosphopeptide-enrichment strategies. We found 161 unique phosphorylated sites in 161 phosphopeptides from 151 proteins, most of which are associated with binding and catalytic activity. Most of the poplar phosphoproteins have orthologs in Arabidopsis, suggesting that there are similar signaling pathways mediated by phosphorylation in poplar and Arabidopsis. However, some phosphoproteins and phosphorylated sites were unique to poplar, thus confirming the need to obtain phosphoproteome data from poplar. Several phosphorylation motifs were extracted from the dataset by Motif-X. This could provide evidence for the involvement of kinases in phosphorylation of these identified proteins during dormancy in poplar. Further experiments are now required to confirm that these specific kinases interact with the identified phosphoproteins in vivo. A promising way forward is to comprehensively characterize and analyze the dynamics of phosphorylation of poplar proteins in response to environmental changes, using specialized targeted quantitative proteomics tools.

\section{Methods}

\section{Plant materials and chemicals}

Dormant terminal buds were collected from hybrid poplar (Populus simonii $\times$ P. nigra) in Harbin, China,
(E126 $\left.37^{\prime}, \mathrm{N}^{\circ} 5^{\circ} 42^{\prime}\right)$ at the end of December, 2009. Samples were frozen in liquid nitrogen and stored at $-80^{\circ} \mathrm{C}$ until use.

Iodoacetamide (IAA) and dithiothreitol (DTT) were purchased from Acros Organics (Morris Plains, NJ, USA). HPLC-grade acetonitrile (ACN) was obtained from JT Baker (Thomas Scientific, Swedesboro, NJ, USA). HPLCgrade water was prepared using a Milli-Q A10 system from Millipore (Billerica, MA, USA). ModiWed sequencing-grade trypsin was supplied by Promega (Madison, WI, USA). Protease-inhibitor cocktail and the 2-D Quant kit were obtained from Amersham Pharmacia Biotech (Uppsala, Sweden). All other reagents were purchased from Sigma (St Louis, MO, USA).

\section{Preparation of total proteins}

The dormant terminal buds were crushed into a fine powder in liquid nitrogen and resuspended at $-20^{\circ} \mathrm{C}$ in $10 \%$ $(\mathrm{w} / \mathrm{v})$ trichloroacetic acid (TCA) in cold acetone containing $0.07 \%(\mathrm{v} / \mathrm{v}) 2$-mercaptoethanol for at least $2 \mathrm{~h}$. The mixture was centrifuged at $10000 \mathrm{~g}$ at $4^{\circ} \mathrm{C}$ for $1 \mathrm{~h}$, and the precipitates were washed with cold acetone containing $0.07 \%(\mathrm{v} / \mathrm{v}) 2$-mercaptoethanol. The pellets were dried by vacuum centrifugation and dissolved in $7 \mathrm{M}$ urea, $2 \mathrm{M}$ thiourea, $20 \mathrm{mM}$ dithiothreitol, 1\% (v/v) protease-inhibitor cocktail, $0.2 \mathrm{mM} \mathrm{Na}_{2} \mathrm{VO}_{3}$, and $1 \mathrm{mM} \mathrm{NaF}$ at room temperature for $2 \mathrm{~h}$, before centrifugation at $40000 \mathrm{~g}$ at $10^{\circ} \mathrm{C}$ for $1 \mathrm{~h}$. The resulting supernatant was collected and kept at $-80^{\circ} \mathrm{C}$ until further use. The total protein content of the samples was quantified using a 2-D Quant kit.

\section{In-solution protein digestion}

Total proteins were digested as described elsewhere $[111,112]$. Briefly, the total protein solution was adjusted to $\mathrm{pH} 8.5$ with $1 \mathrm{M}$ ammonium bicarbonate. Then, the sample was reduced for $45 \mathrm{~min}$ at $55^{\circ} \mathrm{C}$ by adding DTT to a final concentration of $10 \mathrm{mM}$, and then carboxyamidomethylated by incubation with $55 \mathrm{mM}$ IAA for $30 \mathrm{~min}$ in the dark at room temperature. After this step, $\mathrm{CaCl}_{2}$ was added to a final concentration of $20 \mathrm{mM}$. Then, endoprotease Lys-C was added to a final substrate-to-enzyme ratio of $100: 1$, and this reaction was incubated for $12 \mathrm{~h}$ at $37^{\circ} \mathrm{C}$. The Lys- $\mathrm{C}$ digest was added to $1 \mathrm{M}$ urea containing 100 $\mathrm{mM}$ ammonium bicarbonate, and modified trypsin was added to a final substrate-to-enzyme ratio of 50:1. The trypsin digest was also incubated at $37^{\circ} \mathrm{C}$ for $12 \mathrm{~h}$. After digestion, the peptide mixture was enriched using $\mathrm{TiO}_{2}$ microcolumns for further MS analysis.

\section{Enrichment of phosphorylated peptides using $\mathrm{TiO}_{2}$ microcolumns}

The $\mathrm{TiO}_{2}$ microcolumns were packed as described elsewhere [25]. A small plug of C8 material was stamped out of a 3M Empore C8 extraction disk with a HPLC syringe 
needle and placed to form a frit at the small end of the GELoader tip. The $\mathrm{TiO}_{2}$ beads were suspended in $100 \%$ $\mathrm{ACN}$, and an appropriate volume of this suspension (depending on the size of the column) was loaded into the GELoader tip. Gentle air pressure produced by a plastic syringe was applied to pack the column. The $\mathrm{TiO}_{2}$ microcolumn was equilibrated with loading buffer $(40 \mu \mathrm{l}$; $80 \% \mathrm{ACN} / 5 \% \mathrm{TFA} /$ saturated phthalic acid solution). Immediately, the trypsin-digested peptide mixture diluted in loading buffer was added to the $\mathrm{TiO}_{2}$ microcolumn. Then, the column was washed once with loading buffer $(40 \mu \mathrm{l})$ and three times with washing buffer $(40 \mu \mathrm{l} ; 80 \%$ $\mathrm{ACN} / 2 \% \mathrm{TFA}$ ). The washing and loading buffer contained $80 \%$ ACN organic solvent in order to abrogate the adsorption of peptides to the C8 material [28]. The bound peptides were eluted twice with $40 \mu \mathrm{l}$ ammonium bicarbonate $(\mathrm{pH}>10.5)$, and then with $10 \mu \mathrm{l} 30 \% \mathrm{ACN}$. The eluted phosphopeptides were lyophilized and then dissolved in $1 \%$ formic acid before MS analysis.

\section{NanoUPLC-ESI-MS/MS}

NanoUPLC-ESI-MS/MS was performed with a splitless nanoUPLC (10 kpsi nanoAcquity; Waters) in combination with a Synapt high-definition mass spectrometer with a nanospray ion source (Waters). A symmetric $\mathrm{C}_{18} 5-\mu \mathrm{m}$, $180-\mu \mathrm{m} \times 20-\mathrm{mm}$ pre-column and a BEH $\mathrm{C}_{18} 1.7-\mu \mathrm{m}, 75-$ $\mu \mathrm{m} \times 250$-mm analytical reversed-phase column (Waters) were used. The MassLynx (version 4.1; Waters) program was used for instrument control and data acquisition. The mobile phases were (A) $100 \% \mathrm{H}_{2} \mathrm{O} / 0.1 \%$ formic acid and (B) $100 \% \mathrm{ACN} / 0.1 \%$ formic acid. The samples were dissolved in aqueous $0.1 \%$ formic acid solution and loaded onto the pre-column at a flow rate of $5 \mu \mathrm{l} / \mathrm{min}$ for $3 \mathrm{~min}$. The phosphopeptides were separated by a gradient of 5 $40 \%$ mobile phase B for $90 \mathrm{~min}$ at a flow rate of $200 \mathrm{nl} /$ min, followed by a 10 -min rinse with $90 \%$ mobile phase B. The column was re-equilibrated with the initial conditions for $20 \mathrm{~min}$. The lock mass was delivered from the auxiliary pump of the NanoAcquity pump at a constant flow rate of $400 \mathrm{nl} / \mathrm{min}$ at a concentration of $100 \mathrm{fmol} / \mu \mathrm{l}$ of (Glu1) fibrinopeptide B to the reference sprayer of the NanoLockSpray source from the mass spectrometer. In this study, every sample was analyzed in triplicate. Data-dependent acquisition was carried out in positive ion mode. MS spectra were acquired for $1 \mathrm{~s}$ from mass-to-charge ratios of $(\mathrm{m} / z) 350$ to 1990 . Two of the most intense precursor ions that were doubly or triply charged were selected from $\mathrm{m} / \mathrm{z}$ 350 to 1990 . MS/MS spectra produced by collisioninduced dissociation (CID) were acquired for $2 \mathrm{~s}$ from $\mathrm{m} / \mathrm{z}$ 50 to 1990 . The collision energy was automatically calculated according to peptide charge and $\mathrm{m} / z$; a dynamic exclusion window was applied to prevent the same $\mathrm{m} / \mathrm{z}$ from being selected for 2 min after its acquisition. The candidate phosphopeptides were initially assigned by ESI-
MS/MS using 79.96-Da mass increments per phosphate moiety relative to the unmodified peptides. To detect the phosphopeptides, we utilized the preferred loss of the phosphate group upon collision-induced dissociation. In positive ion tandem MS, an intense neutral loss of $98 \mathrm{Da}$, corresponding to $\mathrm{H}_{3} \mathrm{PO}_{4}$, was observed for peptides containing phosphorylated Ser, Thr, and Tyr residues.

\section{Data analysis and Mascot database search}

The MS/MS data were processed and converted to a pkl file format with ProteinLynx software (Waters), and the resulting pkl file was used to search against the JGI Рopulus trichocarpa v1.1 (http://genome.jgi-psf.org/Poptr1_1/ Poptr1_1.home.html) protein sequence database using an in-house Mascot server (version 1.8) with acetylation in the $\mathrm{N}$-terminus of the protein, carbamidomethylation, methionine oxidation, and phosphorylation of serine/ threonine/tyrosine residues as variable modifications. Two missed cleavage sites were allowed. The search was performed with a peptide mass tolerance of $15 \mathrm{ppm}$ in the $\mathrm{MS}$ and $50 \mathrm{ppm}$ in the MS/MS modes. The false discovery rate (FDR) was $0.00 \%$ for peptide matches above the identity threshold and $0.36-0.85 \%$ for peptide matches above the homology or identity threshold.

\section{Bioinformatics}

Using a custom Perl program, all the phosphoprotein sequences were extracted from protein databases (http:// genome.jgi-psf.org/Poptr1_1/Poptr1_1.home.html) by their protein ID. The Blast2Go program [57] was used to obtain descriptions of protein sequences by a BlastP search against a non-redundant protein database (http://blast. ncbi.nlm.nih.gov/Blast.cgi) with default parameter settings. Protein functions, annotations, and classifications were also examined using gene ontology (GO), GO-EnzymeCode, and InterPro databases and search tools.

The Batch sequence search tool (http://pfam.sanger.ac. uk/search) was applied to obtain Pfam information for identified phosphoproteins. The significantly enriched phosphorylation motifs set was extracted from our phosphopeptide data using the Motif-X algorithm [58]. All phosphorylated peptides with confidently identified phosphorylation sites were used as the data set to extract significantly enriched phosphorylation motifs. The phosphopeptides were centered at the phosphorylated amino acid residues and aligned, and ten positions upstream and downstream of the phosphorylation site were included. In the case of $\mathrm{C}$ - and $\mathrm{N}$-terminal peptides, the sequence was completed to 21 amino acids with the required number of " $\mathrm{X}$ "s, where $\mathrm{X}$ represents any amino acid. As the background data set, protein sequences of the entire genome poplar database Populus trichocarpa v1.1 in Fasta format (in a shortened version due to upload restrictions of $10 \mathrm{MB}$ ) were used. The occurrence threshold was 
set to $5 \%$ of the input data set at a minimum of three peptides, and the probability threshold was set to $\mathrm{P}<10^{-5}$. Amino acid sequences around the phosphorylated amino acid based on the alignment of all the phosphorylation sites were completed by the Weblogo program [113] in the entire identified DTBs data set.

\section{Additional material}

Additional file 1: Nine sheets as follows: Sheet 1: Contents. Sheet 2: Phosphopeptide identification list. Sheet 3: Phosphorylation site list. Sheet 4: Blast results. Sheet 5:Annotation_of_phosphoproteins. Sheet 6: KOG classifications. Sheet 7: Pfam_domain_information. Sheet 8: Source_for_motif_analysis. Sheet 9: pS_motifs.

Additional file 2: Phosphopeptides and phosphorylation sites identified in dormant terminal buds of poplar.

Additional file 3: Detailed information for phosphopeptides and phosphoproteins identified in dormant terminal buds of poplar.

Additional file 4: MS/MS spectra (in a separate file). File contains all the original MS/MS spectra of 161 phosphopeptides identified in this study

Additional file 5: Comparison of singly and doubly phosphorylated peptides.

Additional file 6: Location of phosphorylation sites in characterized conserved domains

Additional file 7: Flowchart for analyzing the conservation of phosphoproteins and phosphosites between poplar and Arabidopsis. Additional file 8: Conserved phosphorylation sites within orthologous proteins. (a) Phosphosites conserved in orthologous proteins. (b) Phosphosites that were not conserved in orthologous proteins

Additional file 9: Unconserved phosphorylation sites within orthologous proteins.

Additional file 10: KOG analysis of identified phosphoproteins and all proteins encoded in Populus trichocarpa genome. (a) Percentage of KOG functional group categories from the identified phosphoproteins and all proteins encoded in Populus trichocarpa genome. (b) Percentage of KOG functional subgroup categories from the identified

phosphoproteins and all proteins encoded in Populus trichocarpa genome.

Additional file 11: Complete list of KOG analysis of phosphoproteins and all proteins encoded in Populus trichocarpa genome.

Additional file 12: Sequence alignment of phosphorylated sites in protein kinases between poplar and Arabidopsis.

Additional file 13: Detailed information for identified phosphoproteins referred to in discussion section.

Additional file 14: Sequence alignment of phosphorylated sites in protein phosphatases between poplar and Arabidopsis.

Additional file 15: Sequence alignment of RPS12 between poplar and Arabidopsis.

Additional file 16: Sequence alignment of conserved N-terminus of elF5A between poplar and Arabidopsis.

Additional file 17: Sequence alignment of conserved C-terminus of EF-1-alpha between poplar and Arabidopsis.

List of abbreviations

DTB: Dormant terminal buds; NanoUPLC: Nano ultra-performance liquid chromatography; Ser: Serine; Thr: Threonine; Tyr: Tyrosine; PTM: Posttranslational modification.

\section{Acknowledgements}

We thank Prof. Bai-Chen Wang for helpful discussions. This work was partially supported by the National Basic Research Priorities Program (Grant No. 2009CB119102), the State Key Program of National Natural Science of China (Grant No. 31030017), doctoral funding from Northeast Forestry University (Grant No. 140-602055), and the Fund for Key Projects and Innovation Teams from Northeast Forestry University (Grant No. DL09EA012). The authors have no conflicts of interest to declare.

\section{Author details}

'State Key Laboratory of Tree Genetics and Breeding (Northeast Forestry University), 26 Hexing Road, Harbin 150040, China. ${ }^{2}$ Laboratory for Chemical Defence and Microscale Analysis, P.O. Box 3, Zhijiang 443200, China. ${ }^{3}$ Shenyang Agricultural University, Dongling Road 120, Shenyang, Liaoning 110866, China. ${ }^{4}$ Institute of Basic Medical Sciences, National Center for Biomedical Analysis, 27 Taiping Road, Beijing 100850, China. ${ }^{5}$ Daqing Branch, Harbin Medical University, Daqing 163319, China.

\section{Authors' contributions}

The study was conceived by CPY and ZGW. CCL and HXW carried out experimental work, participated in data analyses, and drafted the manuscript. CFL and ZYS participated in the design of the study and performed in silico analyses. All authors read and approved the final manuscript.

\section{Competing interests}

The authors declare that they have no competing interests.

Received: 22 April 2011 Accepted: 11 November 2011

Published: 11 November 2011

\section{References}

1. Rohde A, Ruttink T, Hostyn V, Sterck L, Van Driessche K, Boerjan W: Gene expression during the induction, maintenance, and release of dormancy in apical buds of poplar. J Exp Bot 2007, 58:4047-4060

2. Rajeev Arora $\sqcup R$, Tanino Karen: Induction and Release of Bud Dormancy in Woody perennials: A science Comes of Age. Hortscience 2003, 38:911-921.

3. Allona I, Ramos A, Ibá ez C, Contreras R, Casado R, Aragoncillo C: Review. Molecular control of winter dormancy establishment in trees. J Agric Res 2008, 6:201-210.

4. Rohde A, Bhalerao R: Plant dormancy in the perennial context. Trends Plant Sci 2007, 12:217-223.

5. David P Horvath JVA, Chao SWun, Foley EMichael: Knowing when to grow: signals regulating bud dormancy. Trends Plant Sci 2003, 8:534-540.

6. Anderson J, Chao W, Horvath D, USDA A: A current review on the regulation of dormancy in vegetative buds. Weed Sci 2001, 49:581-589.

7. Druart N, Johansson A, Baba K, Schrader J, Sj din A, Bhalerao R, Resman L, Trygg J, Moritz T, Bhalerao R: Environmental and hormonal regulation of the activity-dormancy cycle in the cambial meristem involves stagespecific modulation of transcriptional and metabolic networks. Plant J 2007, 50:557-573.

8. Campbell M, Segear E, Beers L, Knauber D, Suttle J: Dormancy in potato tuber meristems: chemically induced cessation in dormancy matches the natural process based on transcript profiles. Funct Integr Genomics 2008, 8:317-328

9. Schrader J, Moyle R, Bhalerao R, Hertzberg M, Lundeberg J, Nilsson P, Bhalerao R: Cambial meristem dormancy in trees involves extensive remodelling of the transcriptome. Plant J 2004, 40:173-187.

10. Ruttink T, Arend M, Morreel K, Storme V, Rombauts S, Fromm J, Bhalerao R, Boerjan W, Rohde A: A molecular timetable for apical bud formation and dormancy induction in poplar. Plant Cell 2007, 19:2370-2390.

11. Mathiason K, He D, Grimplet J, Venkateswari J, Galbraith D, Or E, Fennell A: Transcript profiling in Vitis riparia during chilling requirement fulfillment reveals coordination of gene expression patterns with optimized bud break. Funct Integr Genomics 2009, 9:81-96

12. Mazzitelli L, Hancock R, Haupt S, Walker P, Pont S, McNicol J, Cardle L, Morris J, Viola R, Brennan R: Co-ordinated gene expression during phases of dormancy release in raspberry (Rubus idaeus L.) buds. J Exp Bot 2007, 58:1035-1045.

13. Paradela A, Albar J: Advances in the Analysis of Protein Phosphorylation. J Proteome Res 2008, 7:1809-1818. 
14. Schulze W: Proteomics approaches to understand protein phosphorylation in pathway modulation. Curr Opin Plant Biol 2010, 13:280-287.

15. White FM: Quantitative phosphoproteomic analysis of signaling network dynamics. Curr Opin Biotechnol 2008, 19:404-409.

16. Linding $R$, Jensen $L$, Ostheimer $G$, van Vugt $M$, Jorgensen $C$, Miron I, Diella F, Colwill K, Taylor L, Elder K: Systematic discovery of in vivo phosphorylation networks. Cell 2007, 129:1415-1426.

17. Mann M, Ong S, Grønborg M, Steen H, Jensen O, Pandey A: Analysis of protein phosphorylation using mass spectrometry: deciphering the phosphoproteome. Trends Biotechnol 2002, 20:261-268.

18. Schmelzle K, White FM: Phosphoproteomic approaches to elucidate cellular signaling networks. Curr Opin Biotechnol 2006, 17:406-414.

19. van Bentem S, Roitinger E, Anrather D, Csaszar E, Hirt H: Phosphoproteomics as a tool to unravel plant regulatory mechanisms. Physiol Plant 2006, 126:110-119.

20. de la Fuente van Bentem S, Hirt H: Using phosphoproteomics to reveal signalling dynamics in plants. Trends Plant Sci 2007, 12:404-411.

21. Peck S: Phosphoproteomics in Arabidopsis: moving from empirical to predictive science. J Exp Bot 2006, 57:1523-1527.

22. Sugiyama N, Nakagami H, Mochida K, Daudi A, Tomita M, Shirasu K, Ishihama $Y$ : Large-scale phosphorylation mapping reveals the extent of tyrosine phosphorylation in Arabidopsis. Mol Syst Biol 2008, 4:1-7.

23. Aebersold R, Mann M: Mass spectrometry-based proteomics. Nature 2003, 422:198-207.

24. Zhou H, Watts J, Aebersold R: A systematic approach to the analysis of protein phosphorylation. Nat Biotechnol 2001, 19:375-378.

25. Larsen $M$, Thingholm $T$, Jensen $O$, Roepstorff $P$, Jorgensen $T$ : Highly Selective Enrichment of Phosphorylated Peptides from Peptide Mixtures Using Titanium Dioxide Microcolumns*. Mol Cell Proteomics 2005, 4:873-886.

26. Klemm C, Otto S, Wolf C, Haseloff R, Beyermann M, Krause E: Evaluation of the titanium dioxide approach for MS analysis of phosphopeptides. $J$ Mass Spectrom 2006, 41:1623-1632.

27. Areces LB, Matafora $V$, Bachi A: Analysis of protein phosphorylation by mass spectrometry. Eur J Mass Spectrom 2004, 10:383-392.

28. Thingholm TE, Jorgensen TJD, Jensen ON, Larsen MR: Highly selective enrichment of phosphorylated peptides using titanium dioxide. Nat Protoc 2006, 1:1929-1935

29. Nühse T, Stensballe A, Jensen O, Peck S: Large-scale analysis of in vivo phosphorylated membrane proteins by immobilized metal ion affinity chromatography and mass spectrometry. Mol Cell Proteomics 2003, 2:1234-1243.

30. Nühse T, Stensballe A, Jensen O, Peck S: Phosphoproteomics of the Arabidopsis Plasma Membrane and a New Phosphorylation Site Database. Plant Cell 2004, 16:2394-2405.

31. Nühse T, Bottrill A, Jones A, Peck S: Quantitative phosphoproteomic analysis of plasma membrane proteins reveals regulatory mechanisms of plant innate immune responses. Plant J 2007, 51:931-940.

32. de la Fuente van Bentem $S$, Anrather D, Roitinger E, Djamei A, Hufnagl T, Barta A, Csaszar E, Dohnal I, Lecourieux D, Hirt H: Phosphoproteomics reveals extensive in vivo phosphorylation of Arabidopsis proteins involved in RNA metabolism. Nucleic Acids Res 2006, 34:3267-3278.

33. Reiland S, Messerli G, Baerenfaller K, Gerrits B, Endler A, Grossmann J, Gruissem W, Baginsky S: Large-scale Arabidopsis phosphoproteome profiling reveals novel chloroplast kinase substrates and phosphorylation networks. Plant Physiol 2009, 150:889-903.

34. Li H, Wong WS, Zhu L, Guo HW, Ecker J, Li N: Phosphoproteomic analysis of ethylene-regulated protein phosphorylation in etiolated seedlings of Arabidopsis mutant ein2 using two-dimensional separations coupled with a hybrid quadrupole time-of-flight mass spectrometer. Proteomics 2009, 9:1646-1661

35. de la Fuente van Bentem S, Anrather D, Dohnal I, Roitinger E, Csaszar E, Joore J, Buijnink J, Carreri A, Forzani C, Lorkovic ZJ, et al: Site-specific phosphorylation profiling of Arabidopsis proteins by mass spectrometry and peptide chip analysis. J Proteome Res 2008, 7:2458-2470.

36. Carroll AJ, Heazlewood JL, Ito J, Millar AH: Analysis of the Arabidopsis cytosolic ribosome proteome provides detailed insights into its components and their post-translational modification. Mol Cell Proteomics $2008,7: 347-369$
37. Niittyla T, Fuglsang AT, Palmgren MG, Frommer WB, Schulze WX: Temporal analysis of sucrose-induced phosphorylation changes in plasma membrane proteins of Arabidopsis. Mol Cell Proteomics 2007, 6:1711-1726.

38. Wolschin F, Weckwerth W: Combining metal oxide affinity chromatography (MOAC) and selective mass spectrometry for robust identification of in vivo protein phosphorylation sites. Plant Methods 2005, 1:1-9.

39. Benschop J, Mohammed S, O'Flaherty M, Heck A, Slijper M, Menke F: Quantitative phosphoproteomics of early elicitor signaling in Arabidopsis. Mol Cell Proteomics 2007, 6:1198-1214.

40. Jones A, MacLean D, Studholme D, Serna-Sanz A, Andreasson E, Rathjen J, Peck S: Phosphoproteomic analysis of nuclei-enriched fractions from Arabidopsis thaliana. J Proteomics 2009, 72:439-451.

41. Agrawal $G$, Thelen J: Large scale identification and quantitative profiling of phosphoproteins expressed during seed filling in oilseed rape. $\mathrm{Mol}$ Cell Proteomics 2006, 5:2044-2059.

42. Whiteman SA, Nuhse TS, Ashford DA, Sanders D, Maathuis FJ: A proteomic and phosphoproteomic analysis of Oryza sativa plasma membrane and vacuolar membrane. Plant J 2008, 56:146-156.

43. Endler A, Reiland S, Gerrits B, Schmidt UG, Baginsky S, Martinoia E: In vivo phosphorylation sites of barley tonoplast proteins identified by a phosphoproteomic approach. Proteomics 2009, 9:310-321.

44. Lu T, Meng L, Yang C, Liu G, Liu G, Ma W, Wang B: A shotgun phosphoproteomics analysis of embryos in germinated maize seeds. Planta 2008, 228:1029-1041.

45. Liu C-C, Lu T-C, Li H-H, Wang H-X, Liu G-F, Ma L, Yang C-P, Wang B-C: Phosphoproteomic identification and phylogenetic analysis of ribosomal P-proteins in Populus dormant terminal buds. Planta 2010, 231:571-581.

46. Stone J, Walker J: Plant protein kinase families and signal transduction. Plant Physiol 1995, 108:451-457.

47. Mackintosh R, Davies S, Clarke P, Weekes J, Glllespie J, Gibb B, Hardie D: Evidence for a protein kinase cascade in higher plants. Eur J Biochem 2005, 209:923-931.

48. Baginsky S, Gruissem W: The chloroplast kinase network: new insights from large-scale phosphoproteome profiling. Mol Plant 2009, 2:1141-1153.

49. Grimsrud PA, den Os D, Wenger CD, Swaney DL, Schwartz D, Sussman MR, Ane JM, Coon JJ: Large-scale phosphoprotein analysis in Medicago truncatula roots provides insight into in vivo kinase activity in legumes. Plant Physiol 2010, 152:19-28.

50. Nakagami H, Sugiyama N, Mochida K, Daudi A, Yoshida Y, Toyoda T, Tomita M, Ishihama Y, Shirasu K: Large-scale comparative phosphoproteomics identifies conserved phosphorylation sites in plants. Plant Physiol 2010, 153:1161-1174.

51. van Bentem SD, Hirt H: Protein tyrosine phosphorylation in plants: more abundant than expected? Trends Plant Sci 2009, 14:71-76.

52. Han G, Ye M, Zou H: Development of phosphopeptide enrichment techniques for phosphoproteome analysis. Analyst 2008, 133:1128-1138.

53. Dunn JD, Reid GE, Bruening ML: Techniques for phosphopeptide enrichment prior to analysis by mass spectrometry. Mass Spectrom Rev 2010, 29:29-54.

54. Bateman A, Birney E, Cerruti L, Durbin R, Etwiller L, Eddy S, Griffiths-Jones S, Howe K, Marshall M, Sonnhammer E: The Pfam protein families database. Nucleic Acids Res 2002, 30:276-280

55. Durek P, Schmidt R, Heazlewood JL, Jones A, MacLean D, Nagel A, Kersten B, Schulze WX: PhosPhAt: the Arabidopsis thaliana phosphorylation site database. An update. Nucleic Acids Res 2010, 38 : D828-834

56. Tuskan G, Difazio S, Jansson S, Bohlmann J, Grigoriev I, Hellsten U, Putnam N, Ralph S, Rombauts S, Salamov A: The genome of black cottonwood, Populus trichocarpa (Torr. \& Gray). Science 2006, 313:1596-1604

57. Conesa A, Gotz S, Garcia-Gomez JM, Terol J, Talon M, Robles M: Blast2GO: a universal tool for annotation, visualization and analysis in functional genomics research. Bioinformatics 2005, 21:3674-3676.

58. Schwartz D, Gygi S: An iterative statistical approach to the identification of protein phosphorylation motifs from large-scale data sets. Nat Biotechnol 2005, 23:1391-1398.

59. Bunney $T$, van Walraven $H$, de Boer $A$ : 14-3-3 protein is a regulator of the mitochondrial and chloroplast ATP synthase. Proc Natl Acad Sci 2001, 98:4249-4254. 
60. Derory J, Leger P, Garcia V, Schaeffer J, Hauser MT, Salin F, Luschnig C, Plomion C, Glossl J, Kremer A: Transcriptome analysis of bud burst in sessile oak (Quercus petraea). New Phytol 2006, 170:723-738.

61. Jimenez S, Li Z, Reighard G, Bielenberg D: Identification of genes associated with growth cessation and bud dormancy entrance using a dormancy-incapable tree mutant. BMC Plant Biol 2010, 10:25.

62. Park S, Keathley DE, Han KH: Transcriptional profiles of the annual growth cycle in Populus deltoides. Tree Physiol 2008, 28:321-329.

63. Jia $Y$, Anderson JV, Horvath DP, Gu YQ, Lym RG, Chao WS: Subtractive cDNA libraries identify differentially expressed genes in dormant and growing buds of leafy spurge (Euphorbia esula). Plant Mol Biol 2006, 61:329-344.

64. Yakovlev IA, Fossdal CG, Junttila O, Skr ppa T: Analysis of gene expression during bud burst initiation in Norway spruce via ESTs from subtracted cDNA libraries. Tree Genet Genomes 2006, 2:39-52.

65. Horvath DP, Anderson JV, Soto-Suarez M, Chao WS: Transcriptome analysis of leafy spurge (Euphorbia esula) crown buds during shifts in welldefined phases of dormancy. Weed Sci 2006, 821-827.

66. Horvath D, Chao W, Suttle J, Thimmapuram J, Anderson J: Transcriptome analysis identifies novel responses and potential regulatory genes involved in seasonal dormancy transitions of leafy spurge (Euphorbia esula L.). BMC Genomics 2008, 9:536.

67. Hedley P, Russell J, Jorgensen L, Gordon S, Morris J, Hackett C, Cardle L, Brennan $R$ : Candidate genes associated with bud dormancy release in blackcurrant (Ribes nigrum L.). BMC Plant Biol 2010, 10:202.

68. Vlad F, Rubio S, Rodrigues A, Sirichandra C, Belin C, Robert N, Leung J, Rodriguez PL, Lauriere C, Merlot S: Protein Phosphatases 2C Regulate the Activation of the Snf1-Related Kinase OST1 by Abscisic Acid in Arabidopsis. Plant Cell 2009, 21:3170-3184.

69. Meyer K, Leube MP, Grill E: A protein phosphatase $2 \mathrm{C}$ involved in $\mathrm{ABA}$ signal transduction in Arabidopsis thaliana. Science 1994, 264:1452-1455.

70. Pang X, Halaly T, Crane O, Keilin T, Keren-Keiserman A, Ogrodovitch A, Galbraith D, Or E: Involvement of calcium signalling in dormancy release of grape buds. J Exp Bot 2007, 58:3249-3262.

71. Osakabe Y, Maruyama K, Seki M, Satou M, Shinozaki K, YamaguchiShinozaki K: Leucine-rich repeat receptor-like kinase1 is a key membrane-bound regulator of abscisic acid early signaling in Arabidopsis. Plant Cell 2005, 17:1105-1119.

72. Leung J, Merlot S, Giraudat J: The Arabidopsis ABSCISIC ACID-INSENSITIVE2 $(A B I 2)$ and $A B I 1$ genes encode homologous protein phosphatases $2 C$ involved in abscisic acid signal transduction. Plant Cell 1997, 9:759-771.

73. Kim MC, Chung WS, Yun DJ, Cho MJ: Calcium and calmodulin-mediated regulation of gene expression in plants. Mol Plant 2009, 2:13-21.

74. Brennan R, Jorgensen L, Hackett C, Woodhead M, Gordon S, Russell J: The development of a genetic linkage map of blackcurrant (Ribes nigrum $\mathrm{L}$.) and the identification of regions associated with key fruit quality and agronomic traits. Euphytica 2008, 161:19-34.

75. Huang X, Xue T, Dai S, Gai S, Zheng C, Zheng G: Genes associated with the release of dormant buds in tree peonies (Paeonia suffruticosa). Acta Physiol Plant 2008, 30:797-806.

76. Anderson JV, Gesch RW, Jia Y, Chao WS, Horvath DP: Seasonal shifts in dormancy status, carbohydrate metabolism, and related gene expression in crown buds of leafy spurge. Plant Cell Environ 2005, 28:1567-1578.

77. Sreekantan L, Mathiason K, Grimplet J, Schlauch K, Dickerson JA, Fennell AY: Differential floral development and gene expression in grapevines during long and short photoperiods suggests a role for floral genes in dormancy transitioning. Plant Mol Biol 2010, 73:191-205.

78. Sheldon C, Hills M, Lister C, Dean C, Dennis E, Peacock W: Resetting of FLOWERING LOCUS C expression after epigenetic repression by vernalization. Proc Natl Acad Sci 2008, 105:2214-2219.

79. Zhang H, Van Nocker S: The VERNALIZATION INDEPENDENCE 4 gene encodes a novel regulator of FLOWERING LOCUS C. Plant J 2002, 31:663-673.

80. Kaur J, Sebastian J, Siddiqi I: The Arabidopsis-mei2-like genes play a role in meiosis and vegetative growth in Arabidopsis. Plant Cell 2006, 18:545-559.

81. Close T: Dehydrins: emergence of a biochemical role of a family of plant dehydration proteins. Physiol Plant 1996, 97:795-803.

82. Allagulova C, Gimalov F, Shakirova F, Vakhitov V: The plant dehydrins: structure and putative functions. Biochemistry (MosC) 2003, 68:945-951.
83. Kosova K, Vitamvas P, Prásil I: The role of dehydrins in plant response to cold. Biol Plant 2007, 51:601-617.

84. Tunnacliffe A, Wise M: The continuing conundrum of the LEA proteins. Naturwissenschaften 2007, 94:791-812.

85. Rorat T: Plant dehydrins-tissue location, structure and function. Cell Mol Biol Lett 2006, 11:536-556.

86. Rinne $P$, Welling $A$, Kaikuranta $P$ : Onset of freezing tolerance in birch (Betula pubescens Ehrh.) involves LEA proteins and osmoregulation and is impaired in an ABA-deficient genotype. Plant Cell Environ 1998, 21:601-611.

87. Rinne PLH, Kaikuranta PLM, van der Plas LHW, van der Schoot C: Dehydrins in cold-acclimated apices of birch (Betula pubescens Ehrh.): production, localization and potential role in rescuing enzyme function during dehydration. Planta 1999, 209:377-388.

88. Puhakainen T, Li C, Boije-Malm M, Kangasj rvi J, Heino P, Palva ET: Shortday potentiation of low temperature-induced gene expression of a Crepeat-binding factor-controlled gene during cold acclimation in silver birch. Plant Physiol 2004, 136:4299-4307.

89. Goday A, Jensen AB, Culianez-Macia FA, Alba MM, Figueras M, Serratosa J, Torrent M, Pages M: The Maize Abscisic Acid-Responsive Protein Rab17 Is Located in the Nucleus and Interacts with Nuclear Localization Signals. Plant Cell 1994, : : 351-360.

90. Jensen AB, Goday A, Figueras M, Jessop AC, Pages M: Phosphorylation mediates the nuclear targeting of the maize Rab17 protein. Plant J 1998, 13:691-697.

91. Riera M, Figueras M, Lopez C, Goday A, Pages M: Protein kinase CK2 modulates developmental functions of the abscisic acid responsive protein Rab17 from maize. Proc Natl Acad Sci 2004, 101:9879-9884.

92. Wang W, Vinocur B, Shoseyov O, Altman A: Role of plant heat-shock proteins and molecular chaperones in the abiotic stress response. Trends Plant Sci 2004, 9:244-252

93. Santamaria ME, Rodriguez R, Ca al MJ, Toorop PE: Transcriptome analysis of chestnut (Castanea sativa) tree buds suggests a putative role for epigenetic control of bud dormancy. Ann Bot 2011, 108:485-498.

94. Wisniewski M, Sauter J, Fuchigami L, Stepien V: Effects of near-lethal heat stress on bud break, heat-shock proteins and ubiquitin in dormant poplar (Populus nigra Charkowiensis $\times$ P. nigra incrassata). Tree Physiol 1997, 17:453-460.

95. Ono E, Hatayama M, Isono Y, Sato T, Watanabe R, Yonekura-Sakakibara K, Fukuchi-Mizutani M, Tanaka Y, Kusumi T, Nishino T: Localization of a flavonoid biosynthetic polyphenol oxidase in vacuoles. Plant J 2006, 45:133-143.

96. Jefferies KC, Cipriano DJ, Forgac M: Function, structure and regulation of the vacuolar $(\mathrm{H}+)$-ATPases. Arch Biochem Biophys 2008, 476:33-42.

97. Duby G, Boutry M: The plant plasma membrane proton pump ATPase: a highly regulated P-type ATPase with multiple physiological roles. Pflugers Arch 2009, 457:645-655.

98. Palmgren MG: Plant plasma membrane H+-ATPases: powerhouses for nutrient uptake. Annu Rev Plant Biol 2001, 52:817-845.

99. Kuromori T, Miyaji T, Yabuuchi H, Shimizu H, Sugimoto E, Kamiya A, Moriyama Y, Shinozaki K: ABC transporter AtABCG25 is involved in abscisic acid transport and responses. Proc Natl Acad Sci 2010, 107:2361-2366.

100. Pighin JA, Zheng $H$, Balakshin $L J$, Goodman IP, Western $T L$, Jetter $R$, Kunst $L$, Samuels AL: Plant cuticular lipid export requires an $A B C$ transporter. Science 2004, 306:702-704.

101. Paw owski TA: Proteomic approach to analyze dormancy breaking of tree seeds. Plant Mol Biol 2010, 73:15-25.

102. Hopkins M, Lampi Y, Wang T, Liu Z, Thompson J: Eukaryotic translation initiation factor $5 \mathrm{~A}$ is involved in pathogen-induced cell death and development of disease symptoms in Arabidopsis. Plant Physiol 2008, 148:479-489.

103. Feng $\mathrm{H}$, Chen $\mathrm{Q}$, Feng J, Zhang J, Yang X, Zuo J: Functional characterization of the Arabidopsis eukaryotic translation initiation factor $5 \mathrm{~A}-2$ that plays a crucial role in plant growth and development by regulating cell division, cell growth, and cell death. Plant Physiol 2007, 144:1531-1545.

104. Lebska M, Ciesielski A, Szymona L, Godecka L, Lewandowska-Gnatowska E, Szczegielniak J, Muszyńska G: Phosphorylation of Maize Eukaryotic Translation Initiation Factor 5A (elF5A) by Casein Kinase 2. J Biol Chem 2010, 285:6217-6226. 
105. Greganova E, Heller M, Bütikofer P: A Structural Domain Mediates Attachment of Ethanolamine Phosphoglycerol to Eukaryotic Elongation Factor 1A in Trypanosoma brucei. PLoS ONE 2010, 5:e9486.

106. Gross S, Kinzy T: Translation elongation factor $1 A$ is essential for regulation of the actin cytoskeleton and cell morphology. Nat Struct Mol Biol 2005, 12:772-778.

107. Peters H, Chang Y, Traugh J: Phosphorylation of elongation factor 1 (EF-1) by protein kinase $\mathrm{C}$ stimulates GDP/GTP-exchange activity. Eur J Biochem 2004, 234:550-556

108. Rinalducci S, Larsen M, Mohammed S, Zolla L: Novel protein phosphorylation site identification in spinach stroma membranes by titanium dioxide microcolumns and tandem mass spectrometry. $J$ Proteome Res 2006, 5:973-982.

109. Klimmek F, Sjodin A, Noutsos C, Leister D, Jansson S: Abundantly and rarely expressed Lhc protein genes exhibit distinct regulation patterns in plants. Plant Physiol 2006, 140:793-804.

110. Hansson M, Vener A: Identification of three previously unknown in vivo protein phosphorylation sites in thylakoid membranes of Arabidopsis thaliana. Mol Cell Proteomics 2003, 2:550-559.

111. Link AJ, Eng J, Schieltz DM, Carmack E, Mize GJ, Morris DR, Garvik BM, Yates JR: Direct analysis of protein complexes using mass spectrometry. Nat Biotechnol 1999, 17:676-682.

112. Washburn MP, Wolters D, Yates JR: Large-scale analysis of the yeast proteome by multidimensional protein identification technology. Nat Biotechnol 2001, 19:242-247.

113. Crooks G, Hon G, Chandonia J, Brenner S: WebLogo: a sequence logo generator. Genome Res 2004, 14:1188-1190.

doi:10.1186/1471-2229-11-158

Cite this article as: Liu et al:: Identification and analysis of

phosphorylation status of proteins in dormant terminal buds of poplar. BMC Plant Biology 2011 11:158.

\section{Submit your next manuscript to BioMed Central and take full advantage of:}

- Convenient online submission

- Thorough peer review

- No space constraints or color figure charges

- Immediate publication on acceptance

- Inclusion in PubMed, CAS, Scopus and Google Scholar

- Research which is freely available for redistribution

Submit your manuscript at www.biomedcentral.com/submit 